\title{
Catalog of small repeating earthquakes for the Japanese Islands
}

\author{
Toshihiro Igarashi* (1)
}

\begin{abstract}
Groups of repeating earthquakes, which occur in approximately the same location and possess a similar focal mechanism, have been extracted in various tectonic environments worldwide. Their recurrence interval has been used to estimate the spatiotemporal evolution of aseismic slip along major tectonic boundaries. Furthermore, slight changes between the waveforms of repeating earthquakes have been analyzed to delineate temporal changes in the local seismic velocity structure. Here, we construct a long-term catalog of small repeating earthquakes in the central Japan since 1981 and throughout the Japanese Islands since 2001 (2001-2019) based on waveform similarity and relative source locations. Most of the long-duration sequences are located near the strongly coupled areas of the Philippine Sea and Pacific plates as they subduct from the Ryukyu-Nankai-Sagami and Kuril-Japan trenches, respectively. Many of the repeating sequences that occur in shallow crustal environments are short-lived. This repeating earthquake catalog allows us to estimate the slip history along each tectonic boundary. We believe that this and similar catalogs will be useful for future investigations of source processes, temporal slip and stress changes along faults, and local velocity structures, thereby providing new insights into earthquake generation mechanisms.
\end{abstract}

Keywords: Small repeating earthquake, Catalog, Plate boundary, Inland area, Japan

\section{Introduction}

Groups of similar earthquakes and repeating earthquakes have been detected in various tectonic environments worldwide (Uchida and Bürgmann 2019). Similar earthquakes are defined as events possessing similar waveforms, and repeating earthquakes consist of similar earthquakes that occur in approximately the same location and possess nearly identical focal mechanisms. Many repeating earthquakes occur regularly at plate boundaries, whereas some occur as short-lived bursttype activity in shallow inland crustal environments (e.g., Igarashi 2010).

Repeating earthquakes are useful for understanding earthquake generation mechanisms, monitoring the local structural changes, and testing the earthquake predictability. Both the spatial distribution and temporal changes

*Correspondence: igarashi@eri.u-tokyo.ac.jp

Earthquake Research Institute, The University of Tokyo, 1-1-1 Yayoi, Bunkyo-ku, Tokyo, Japan in their source processes have been revealed via analyses of repeating earthquakes (e.g., Okada et al. 2003; Ariyoshi et al. 2014). The earthquake repetition over a long period is used to estimate the spatiotemporal evolution of interplate aseismic slip (e.g., Igarashi 2010; Kato et al. 2016) and test the earthquake predictability (e.g., Uchida and Bürgmann 2019). Slight changes among the waveforms of repeating earthquakes often indicate temporal changes in the local seismic structure (e.g., Niu et al. 2003; Rubinstein et al. 2007; Taira et al. 2009; Tkalčić et al. 2013). The matched filter technique can detect frequent repetitive sources embedded in the seismic record, even if the waveforms have undergone moderate changes, and thereby improves the completeness of the hypocenter catalog (e.g., Kato and Nakagawa 2014). Nearby earthquakes can also be efficiently extracted from high-seismicity areas where many of the earthquakes possess similar waveforms.

Early approaches to similar earthquake extraction were based on the visual inspection of seismogram records 
(e.g., Omori 1905; McEvilly and Casaday 1967; Stauder and Ryall 1967; Tsujiura 1973; Hamaguchi and Hasegawa 1975; Geller and Mueller 1980). Their recurrence at approximately the same location was investigated using other information, such as the S-P time, which is the time difference between the $\mathrm{P}$ - and S-wave arrivals (e.g., Hamaguchi and Hasegawa 1975), and the source size, which is estimated from the corner frequency (e.g., Geller and Mueller 1980).

Large-scale analyses of similar earthquakes based on waveform similarity have been made possible by the accumulation of vast digital seismogram data volumes and advanced computing capabilities. Aster and Scott (1993) investigated the features related to waveform similarity using 4569 seismic records from ten seismic stations in the ANZA network (Southern California, USA) over a 9.5-year period (October 1, 1982 to April 14, 1992). Those authors analyzed $1,121,332$ earthquake pairs with an inter-event distance of $\leq 10 \mathrm{~km}$, and identified similar earthquakes when the earthquake pairs had a median cross-correlation coefficient of $\geq 0.725$. They detected 290 similar earthquake sequences (1255 events) based on the threshold.

Schaff and Richards (2004) extracted similar earthquakes from $\sim 14,000$ earthquakes that occurred in China between 1985 and 2000 using 130,000 waveforms that were recorded at 115 neighboring seismic stations. The maximum interevent distance was $150 \mathrm{~km}$, resulting in $\sim 1,200,000$ analyzed earthquake pairs. Similar earthquakes were identified when the cross-correlation coefficient between an earthquake pair was $\geq 0.8$ at a given station. They detected 494 similar earthquake sequences (1303 events).

Igarashi (2010) identified similar earthquakes throughout the Japanese Islands using waveforms obtained from a nationwide seismic network over an 8-year period (January 2002 to December 2009). He analyzed 428,156,998 earthquake pairs using the waveforms from 168,425 earthquakes that were recorded by up to 1105 stations. Similar earthquakes were identified when the cross-correlation coefficient was $\geq 0.95$ at two or more stations. This paper detected 2356 similar earthquake sequences (6638 events).

Dodge and Walter (2015) extracted similar earthquakes using global seismic data from the Lawrence Livermore National Laboratory waveform database over a 43-year period (1970-2013). They analyzed $\sim 310,000,000$ waveforms from 3,745,879 events and 6266 seismic stations, with $\sim 1,485,000,000$ event pairs possessing an interevent distance of $\leq 50 \mathrm{~km}$. Similar earthquakes were determined when the correlation coefficient was $\geq 0.6$ at any station. The number of events exceeding the threshold was $14.5 \%$ of the total $(542,405$ events).
Several studies have investigated the degree of colocation or overlap between the source areas of each earthquake pair to accurately identify repeating earthquakes. For example, Lees (1998) used the travel time difference obtained via cross-spectral and coherence calculations. Chen et al. (2008) also validated the overlap between two source areas by imposing the following conditions: the cross-correlation coefficient is $\geq 0.85$ and the S-P time is $<0.012 \mathrm{~s}$. Li et al. (2011) extracted candidates for repeating earthquakes when the relative distance calculated from the S-P differential times and assumed velocity structure was less than the rupture dimensions of each earthquake.

Here, we update the similar earthquake catalog that was constructed by Igarashi (2010) to analyze the longterm earthquake activity throughout the Japanese Islands that is associated with the subducting Pacific and Philippine Sea plates, and overriding Amur and Okhostk plates. Furthermore, we improve this small repeating earthquake catalog by imposing the colocation or overlapping constraints onto the rupture areas of each similar earthquake pair. We then compare these two catalogs in terms of the average slip rate distribution along the entire Japanese Islands.

\section{Methods}

We basically followed the same procedure as proposed by Igarashi (2010) for detecting similar earthquakes. This procedure calculates the cross-correlation coefficients between the observed seismograms at each station. We first picked up all of the earthquake pairs with an epicentral separation of $\leq 20 \mathrm{~km}$. The time window included waveform data from the P-wave onset to $3 \mathrm{~s}$ after the direct $\mathrm{S}$-wave arrival, with the maximum time window duration and epicentral distance set to $50 \mathrm{~s}$ and $400 \mathrm{~km}$, respectively. We then bandpass-filtered the waveforms prior to the cross-correlation coefficient calculation using 1-4, 2-8, and $4-16 \mathrm{~Hz}$ passbands. Similarities are identified in $1-4 \mathrm{~Hz}$ passband for $M \geq 3$ earthquakes, in 1-4 and 2-8 $\mathrm{Hz}$ passbands for M2.5-2.9 earthquakes, and at all passbands for $M<2.5$ earthquakes. The selected passbands are set as the quarter wavelength of the $\mathrm{S}$ wave, which roughly corresponds to the source size of the analyzed earthquake, as shown in Igarashi et al. (2003). A candidate for a repeating pair is selected when their cross-correlation coefficients are $\geq 0.95$ at two or more stations.

The colocation or overlap of the source areas must be confirmed to identify repeating earthquakes. However, the resolution of the source process analysis depends on the station network geometry, fault plane setting, assumed seismic velocity structure, and analysis method. The source size depends on the assumed stress drop. 
Most interplate earthquakes occur in the subduction zone offshore of the Japanese Islands, which makes it difficult to determine the exact source process such as hypocenter and main moment release area using the current land-based seismic network. Therefore, we searched for pairs that satisfied both the waveform similarity and small S-P differential time thresholds to extract the repeating earthquakes, as proposed in previous studies (Chen et al. 2008; Li et al. 2011).

We computed the S-P differential times for the earthquake pairs that satisfied the above-mentioned waveform similarity criterion. A 2-s time window was used for both the P- and S-arrival computations. We assumed a circular patch model with a constant stress drop of $3 \mathrm{MPa}$ to calculate the radius of each event. We identified a repeating pair when the median value of the S-P differential time between the event pairs for stations with the crosscorrelation coefficients of $\geq 0.6$ was less than the time difference estimated from the source radii and P- and $\mathrm{S}$-wave velocity structures at the hypocentral depths of the event pair. Events were grouped into the same repeating earthquake sequence when multiple pairs shared the same event. Figure 1 shows an example of a repeating earthquake sequence identified in the present study. Note that the waveforms of these repeating earthquakes are very similar to each other, despite the occurrence of the Mw 9.0 Tohoku-Oki Earthquake in March 2011. The normalized amplitude shown on the right does not correspond to the magnitude shown on the left. This may be due to the magnitude uncertainty and/or the difference in frequency characteristics of each earthquake.

The observed repeating earthquake patterns can be roughly classified as either continual- or burst-type events (Igarashi et al. 2003). Continual-type events occur at an approximately constant recurrence interval throughout the analyzed period, whereas burst-type events only occur over short periods, generally spanning from 1 day to several months.

\section{Data}

The seismogram records used in this analysis were selected from the seismic stations operated by the National Research Institute for Earth Science and Disaster Resilience (NIED) (National Research Institute for Earth Science and Disaster Resilience 2019), Japan Meteorological Agency (JMA), and Earthquake Research Institute (ERI) of the University of Tokyo. We used vertical component seismograms from $M \geq 1.5$ earthquakes in the JMA hypocenter catalog for the period from July 11, 2000 to December 18, 2019. The hypocenter information reported by ERI was used to extend the analysis period to July 18, 1981. We computed the cross-correlation functions for $\sim 39$ billion earthquake pairs from 1523 seismic stations and 1,080,664 events. Figure 2 shows the starting time of our analysis across the Japanese Islands. The ERI regional earthquake catalog allowed us to extend the central Japan analysis to the 1980s. The target area has continued to expand since the start of the study period due to the addition of new seismic stations and instrument upgrades to the seismic networks, with the seismic networks spanning the entire Japanese Islands since 2001.

\section{Results}

The spatial distribution of 11,677 similar earthquake sequences (41,735 events), which were extracted using the cross-correlation coefficient information, is shown in Fig. 3a, and the spatial distribution of 10,019 repeating earthquake sequences $(36,029$ events), which were verified by their small $\mathrm{S}-\mathrm{P}$ difference times, is shown in Fig. 3b. These catalogs can be provided in Additional files 1,2 .

The spatial distribution of similar and repeating earthquakes is basically the same as that in Igarashi (2010). Most of the long-duration, continual-type sequences are located in inter-plate coupling areas on the Philippine Sea and Pacific plates as they subduct from the RyukyuNankai-Sagami and Kuril-Japan trenches, respectively. The focal mechanisms for most of the continual-type sequences, which are derived from the F-net moment tensor solutions (Fukuyama et al. 1998), indicate lowangle thrust faulting and reveal the dip angles of the plate boundaries. Conversely, many of the inland shallow sequences are short-lived ( $\leq 1$ day).

Approximately $86 \%$ of the similar earthquakes match with repeating earthquakes. Approximately $54 \%$ of the earthquakes (3067 events) that were excluded from the repeating earthquake catalog occurred at shallow crustal depths beneath the Japanese Islands. Earthquakes that either occurred immediately after large earthquakes or were detected in poor observational environments due to low signal-to-noise ratios also tended to be excluded from the repeating earthquake catalog. While $\sim 42 \%$ of the excluded earthquakes (2389 events) occurred before 2001, the repeating earthquakes during this early period (1981-2000) with limited seismic network coverage accounted for only $\sim 7 \%$ of the repeating earthquake catalog, indicating that the excluded earthquakes do not have a strong impact on the overall behavior of repeating earthquakes in the region. No noticeable magnitude dependence was found between similar and repeating earthquake catalogs. In M1.5-1.9, approximately $84 \%$ of the similar earthquakes match with repeating earthquakes. 


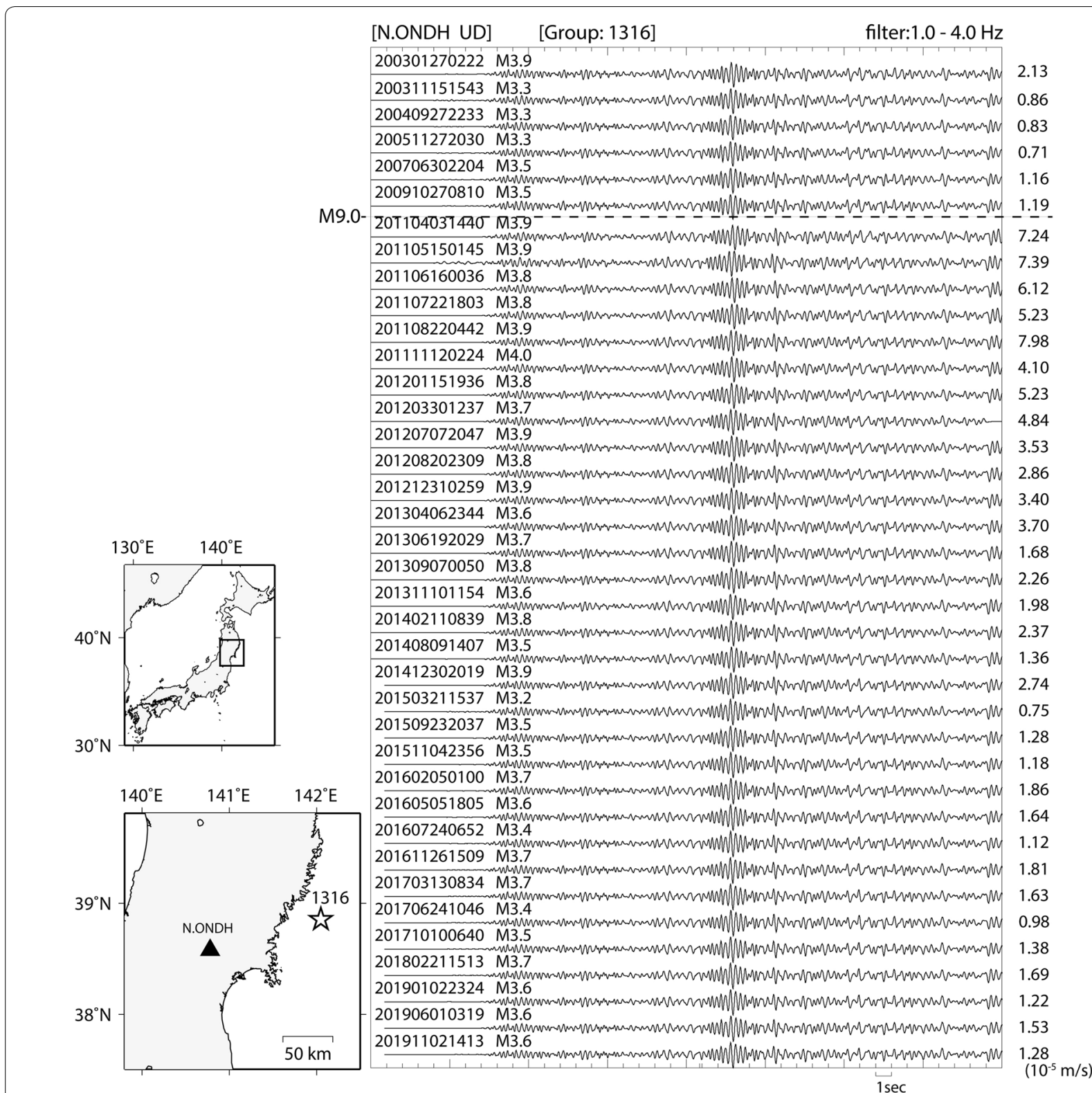

Fig. 1 Example of vertical component waveforms for a small repeating earthquake sequence. The 1-4 Hz bandpass-filtered waveforms are shown. The onset (YYYMMDDHHMMSS format) and JMA magnitude of each earthquake are listed on the left side of each trace. Each trace is normalized by the maximum amplitude, which is shown at right. The timing of the $2011 \mathrm{Mw} 9.0$ Tohoku-Oki Earthquake is indicated by the dashed line. The inset map shows the locations of the repeating earthquake sequence (Group 1316; star) and the seismic station that recorded the waveforms (N.ONDH; triangle)

\section{Discussion}

We have constructed two earthquake catalogs based on waveform similarity. One could argue that there would be a systematic difference between the interplate aseismic slip and/or slip rate estimated from the two catalogs. Therefore, we investigated the differences in the spatial distribution of slip rate between the catalogs. We basically applied the same procedure as that used by Igarashi
(2010) to each catalog to estimate the interplate slip rate. The amount of slip for each event was calculated from the relationship between seismic moment and slip, as proposed by Nadeau and Johnson (1998). The scalar moment was converted from magnitude using a magnitude-scalar moment relationship (Hanks and Kanamori 1979). We assumed that the slip rate within each interseismic period of repeating sequences was constant, based on 

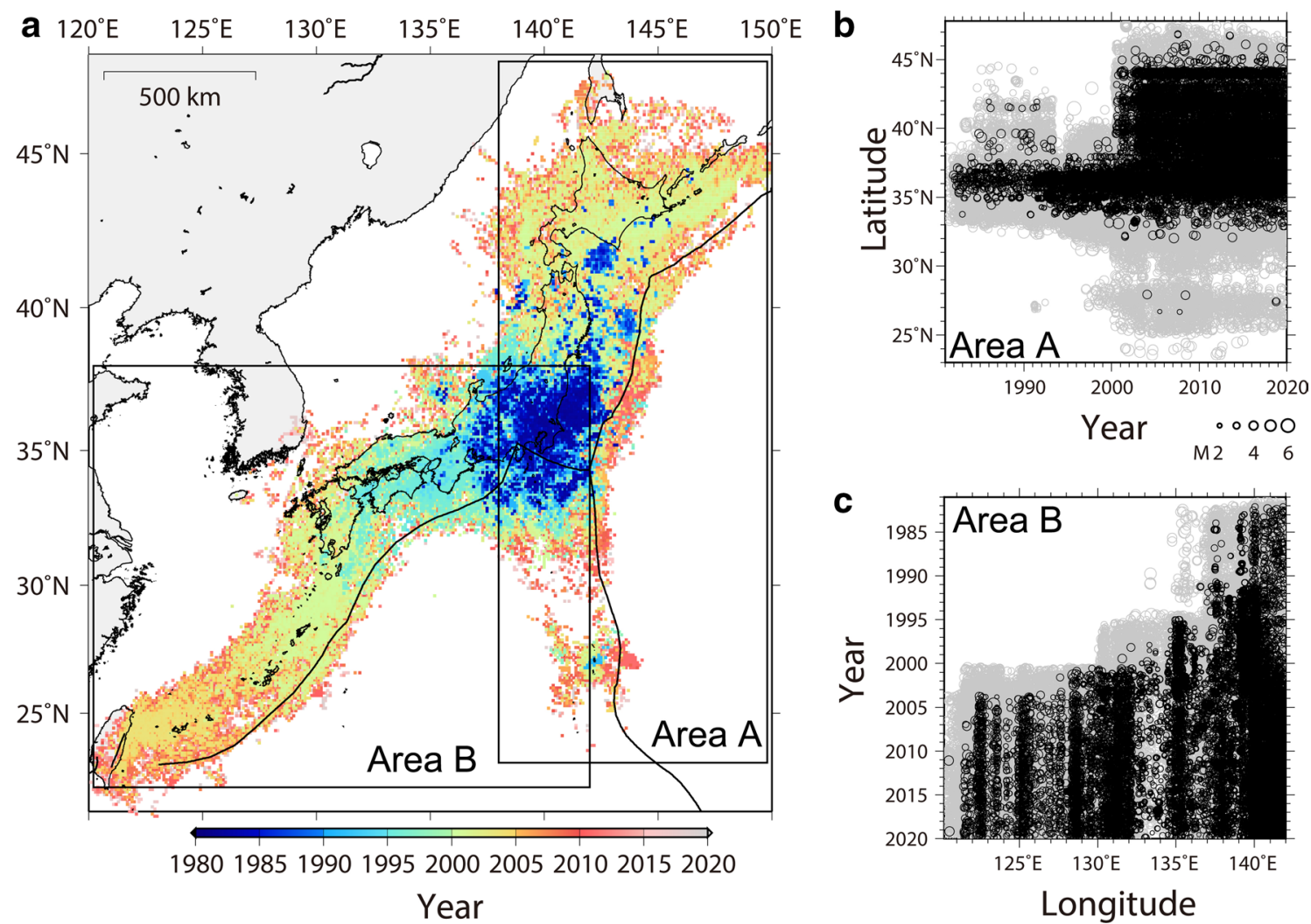

Fig. 2 a Timing of the first analyzed events across the study region. $\mathbf{b}$ Latitude-time diagram for Area A. c Longitude-time diagram for Area B. Black and gray symbols denote the similar earthquakes and analyzed earthquakes, respectively
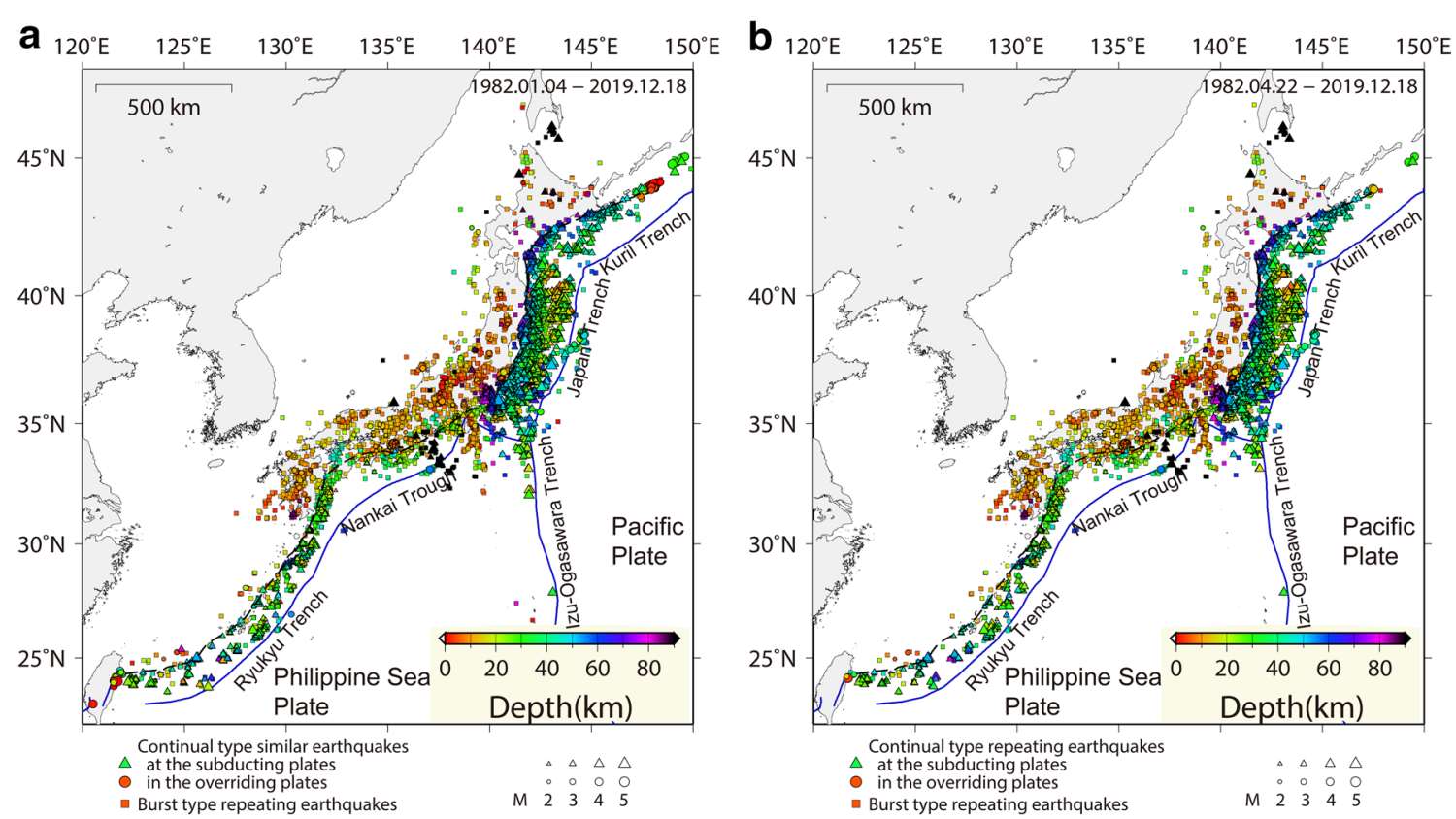

Fig. 3 Spatial distributions of $\mathbf{a}$ similar earthquakes and $\mathbf{b}$ small repeating earthquakes in Japan. Dashed lines indicate the downdip limit of interplate coupling (Igarashi et al. 2001) 
the slip-predictable earthquake model (e.g., Shimazaki and Nakata 1980). The average slip rate was extrapolated when either the previous or subsequent earthquake would have occurred outside of the analysis period.

Figure 4a and d shows the spatial distributions of the average slip rates for the 19-year period since 2001 based on the similar earthquake catalog, and Fig. 4b, e shows the corresponding results based on the repeating earthquake catalog. Figure 4c, $\mathrm{f}$ shows the differences in the estimated average slip rates between the two catalogs. While the slip-rate changes in some areas are due to a decrease in the number of extracted repetitive earthquakes, the relative lateral slip-rate variations are quite similar between the two sets of results. Furthermore, there are only minor absolute differences in the slip rates (generally $<10 \mathrm{~mm} /$ year). Therefore, the differences between the two catalogs are not significant enough to change the interpretation on the interplate aseismic slip
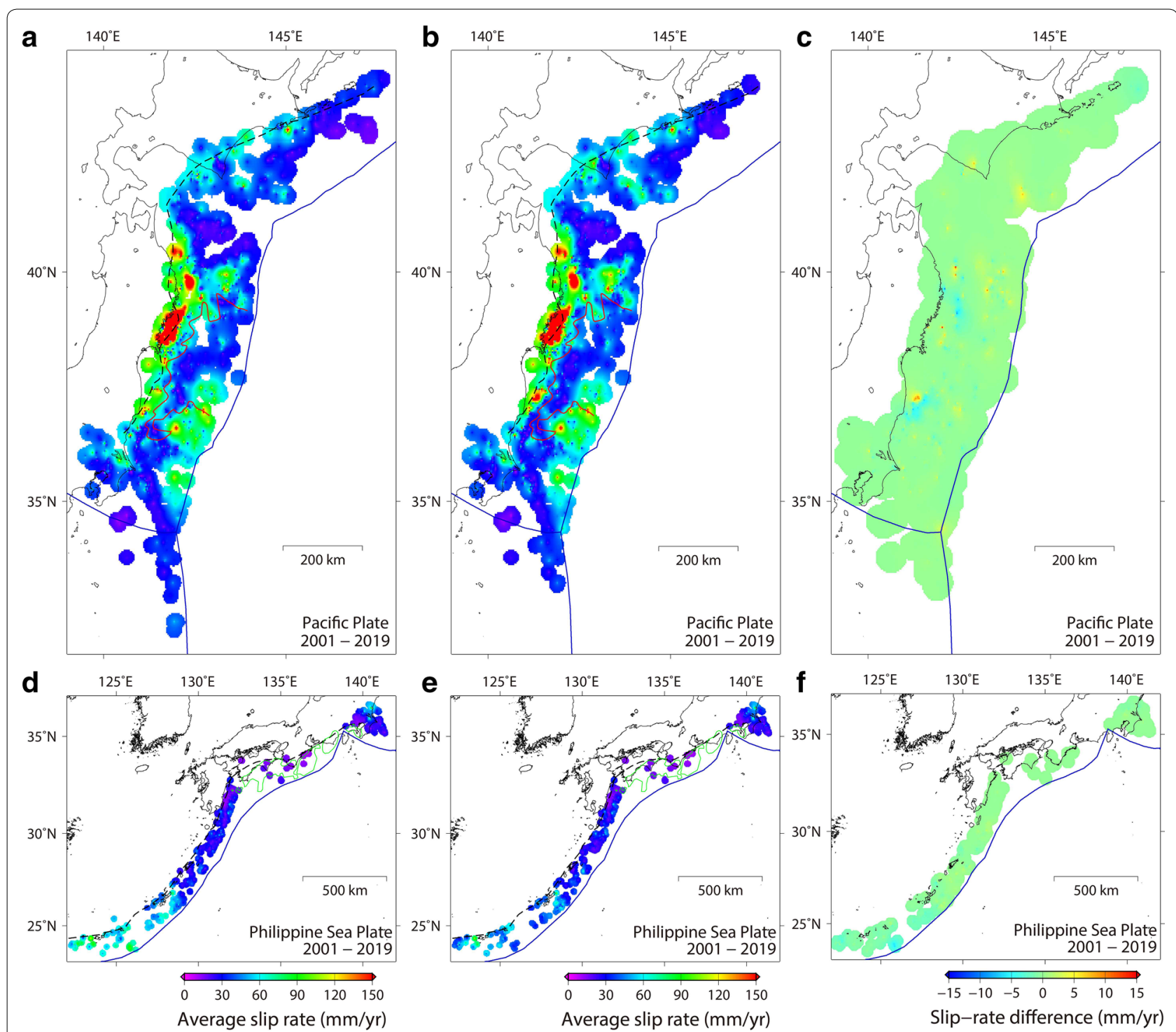

Fig. 4 Average slip rates estimated from similar and repeating earthquakes during the 2001-2019 period, and their differences. a, d Average slip rates estimated from similar earthquakes. $\mathbf{b}$, e Average slip rates estimated from repeating earthquakes. $\mathbf{c}, \mathbf{f}$ Slip rate differences. $\mathbf{a}-\mathbf{c}$ are for the subducting Pacific Plate, and $\mathbf{d}-\mathbf{f}$ are for the subducting Philippine Sea Plate. Dashed lines indicate the downdip limit of interplate coupling (Igarashi et al. 2001). Blue lines indicate plate boundaries. Red line in $\mathbf{a}$ and $\mathbf{b}$ denotes the outer edge of the large slip zone during the 2011 Tohoku-Oki Earthquake rupture (Kato and Igarashi 2012). Green lines in $\mathbf{d}$ and $\mathbf{e}$ indicate the asperities of large interplate earthquakes on the subducting Philippine Sea Plate (Baba and Cummins 2005; Sato et al. 2005) and the potential source region of the anticipated Tokai Earthquake (Central Disaster Management Council 2001) 
of Igarashi (2010), which is based on slip rates estimated from a similar earthquake catalog.

Figure 4 extends the time series for determining the average slip rates across the Japanese Islands from 2010 (Fig. 2 of Igarashi 2010) to 2019, thereby allowing temporal changes in the average slip rates to be inferred. The areas where large earthquakes did not occur during the analysis period are illuminated by either large slip deficits during the interseismic periods or a lack of slip areas. The slip rate has decreased around the source region of the 2003 Mw 8.0 Tokachi-Oki Earthquake due to the decay of the afterslip signal. The slip rates in many areas are lower than those reported by Igarashi (2010), possibly reflecting the extended time series and better-constrained recurrence intervals. However, our results reiterate the observation of Igarashi (2010) that it is not yet possible to determine the slip rate distribution along most of the Nankai Trough and the shallow depths of the Kuril Trench where no similar/repeating earthquakes have been detected to date.

The area of large coseismic slip relating to the 2011 Tohoku-Oki Earthquake (Kato and Igarashi 2012), as indicated by the red line in Fig. 4a, b, is another area that did not host significant aseismic slip. Conversely, the slip rates of the surrounding areas have been higher due to the after-slip induced by the Tohoku-Oki Earthquake; the higher slip rates in the downdip (deeper) extension of the large area of coseismic slip are particularly notable. This slip acceleration on the Pacific Plate boundary extends from $\sim 40^{\circ} \mathrm{N}$ to the southern limit of the Japan Trench. The slip rate also increased locally at the northeastern edge of the Philippine Sea Plate.

Similar earthquakes have not been detected during the early time period in several regions (e.g., 2000-2003 in Ryukyu Islands) despite the available seismic waveform records. The extraction of similar earthquakes may be affected by temporal changes in the frictional properties of the source region, the velocity structure along the propagation path, and the equipment at each seismic station. The similar earthquakes extracted in this analysis account for only $\sim 4 \%$ of the total number of analyzed earthquakes. We should therefore investigate the causes of the variations in the correlation coefficient values of adjacent earthquakes in greater detail.

The repeating earthquake sequences at the plate boundary are considered to be caused by repeated slip on small asperities that are surrounded by aseismic slip (creeping) areas (e.g., Chen and Lapusta 2009). This indicates that we can monitor fault creep at depth using waveform data. However, the interactions between repeating earthquakes and other earthquakes (e.g., static and dynamic stress transfer) are poorly understood. Furthermore, our analysis period is much shorter than the recurrence interval of large earthquakes. Long-term seismic monitoring networks are therefore essential to advancing our understanding of complex slip behavior on faults.

The present analysis and compilation of similar/ repeating earthquakes throughout Japan are ongoing, with the waveform and hypocenter information, along with the similar/repeating earthquake results, being updated daily and stored in our detection system. The cross-correlation coefficient calculation can be optimized using precisely determined hypocenters and incorporating the information on existing similar earthquakes. Relative hypocenter information would improve the accuracy of the extracted similar earthquakes and provide more detailed earthquake recurrence characteristics. It is therefore desirable to use precisely determined hypocenters in the detection system in the future. At that timing, we must consider how to maintain event files from multiple catalogs and links to this information. A more detailed investigation of the operational conditions of the seismic stations and their acquired waveforms is also needed for the efficient detection of repeating earthquakes.

We believe that these similar/repeating earthquake catalogs will be invaluable in future diagnoses of the source processes, slip, and stress changes along faults, local structural changes, and test of earthquake predictability, thereby providing further insights into complex fault behavior.

\section{Supplementary information}

Supplementary information accompanies this paper at https://doi. org/10.1186/s40623-020-01205-2.

Additional file 1. Table of similar earthquakes. Group ID, Date, Latitude, Longitude, Depth, Magnitude and the Cross-correlation coefficient are provided for each earthquake here.

Additional file 2. Table of small repeating earthquakes. Group ID, Date, Latitude, Longitude, Depth, and Magnitude are provided for each earthquake here.

\section{Abbreviations}

ERI: Earthquake Research Institute; JMA: Japan Meteorological Agency; NIED: National Research Institute for Earth Science and Disaster Resilience.

\section{Acknowledgements}

We thank the National Research Institute for Earth Science and Disaster Resilience (NIED) (National Research Institute for Earth Science and Disaster Resilience 2019), Japan Meteorological Agency (JMA), and Earthquake Research Institute (ERI) of the University of Tokyo for allowing us to use the waveform data from their seismic networks. We also thank JMA for providing the hypocenter catalogs. We are grateful to A. Kato for the useful and constructive discussions. The figures in this paper were created using Generic Mapping Tools (Wessel and Smith 1998). This work was supported by the Ministry of Education, Culture, Sports, Science and Technology of Japan, under its Earthquake and Volcano Hazards Observation and Research Program. 


\section{Authors' contributions}

$\mathrm{TI}$ conducted the data analysis and interpretation of the results, and drafted the manuscript. The author read and approved the final manuscript.

\section{Funding}

This work was supported by the Ministry of Education, Culture, Sports, Science and Technology of Japan, under its Earthquake and Volcano Hazards Observation and Research Program.

\section{Availability of data and materials}

The waveform data used in this study are available from NIED (https://hinet www11.bosai.go.jp/auth/?LANG=en), JMA (http://www.data.jma.go.jp/svd/ eqev/data/bulletin/index_e.html, http://www.data.jma.go.jp/svd/egev/data/ daily_map/index.html), and ERI (http://tkypub.eri.u-tokyo.ac.jp/harvest). The hypocenter catalogs used in this study are available from JMA (http://www. data.jma.go.jp/svd/egev/data/bulletin/index_e.html, http://www.data.jma. go.jp/svd/eqev/data/daily_map/index.html).

\section{Ethics approval and consent to participate}

Not applicable.

\section{Consent for publication}

Not applicable.

\section{Competing interests}

The author declare no competing interests.

Received: 24 March 2020 Accepted: 19 May 2020

Published online: 29 May 2020

\section{References}

Ariyoshi K, Uchida N, Matsuzawa T, Hino R, Hasegawa A, Hori T, Kaneda Y (2014) A trial estimation of frictional properties, focusing on aperiodicity off Kamaishi just after the 2011 Tohoku earthquake. Geophys Res Lett. https://doi.org/10.1002/2014GL061872

Aster RC, Scott J (1993) Comprehensive characterization of waveform similarity in microearthquake data sets. Bull Seismol Soc Am 83:1307-1314

Baba T, Cummins PR (2005) Contiguous rupture areas of two Nankai Trough earthquakes revealed by high-resolution tsunami waveform inversion. Geophys Res Lett. https://doi.org/10.1029/2004GL022320

Central Disaster Management Council (2001) Report on the Tokai Earthquake by organization for technical investigation in Central Disaster Management Council. http://www.bousai.go.jp/kaigirep/chuobou/3/pdf/siryo 2-2.pdf. Accessed 27 May 2020. (in Japanese)

Chen T, Lapusta N (2009) Scaling of small repeating earthquakes explained by interaction of seismic and aseismic slip in a rate and state fault model. J Geophys Res 114:B01311. https://doi.org/10.1029/2008JB005749

Chen KH, Nadeau RM, Rau R-J (2008) Characteristic repeating earthquakes in an arc-continent collision boundary zone: the Chihshang fault of eastern Taiwan. Earth Planet Sci Lett 276:262-272

Dodge DA, Walter WR (2015) Initial global seismic cross-correlation results: implications for empirical signal detectors. Bull Seismol Soc Am. https:// doi.org/10.1785/0120140166

Fukuyama E, Ishida S, Dreger DS, Kawai H (1998) Automated seismic moment tensor determination by using on-line broadband seismic waveforms. Zisin 51:149-156 (in Japanese with English Abstract)

Geller GJ, Mueller CS (1980) For similar earthquakes in central California. Geophys Res Lett 7:821-824

Hamaguchi H, Hasegawa A (1975) Recurrent occurrence of the earthquakes with similar wave forms and its related problems. J Seismol Soc Jpn 28:153-169

Hanks TC, Kanamori H (1979) A Moment magnitude scale. J Geophys Res 84(B5):2348-2350

Igarashi T (2010) Spatial changes of inter-plate coupling inferred from sequences of small repeating earthquakes in Japan. Geophys Res Lett. https://doi.org/10.1029/2010GL044609
Igarashi T, Matsuzawa T, Umino N, Hasegawa A (2001) Spatial distribution of focal mechanisms for interplate and intraplate earthquakes associated with the subducting Pacific plate beneath the northeastern Japan arc: a triple-planed deep seismic zone. J Geophys Res 106:2177-2191

Igarashi T, Matsuzawa T, Hasegawa A (2003) Repeating earthquakes and interplate aseismic slip in the northeastern Japan subduction zone. J Geophys Res. https://doi.org/10.1029/2002JB001920

Kato A, Igarashi T (2012) Regional extent of the large coseismic slip zone of the 2011 Mw 9.0 Tohoku-Oki earthquake delineated by on-fault aftershocks. Geophys Res Lett 39:L15301. https://doi.org/10.1029/2012gl052220

Kato A, Nakagawa S (2014) Multiple slow-slip events during a foreshock sequence of the 2014 lquique, Chile, Mw8.1 earthquake. Geophys Res Lett. https://doi.org/10.1002/2014gl061138

Kato A, Fukuda J, Kumazawa T, Nakagawa S (2016) Accelerated nucleation of the 2014 lquique, Chile Mw 8.2 Earthquake. Sci Rep 6:24792. https://doi. org/10.1038/srep24792

Lees JM (1998) Multiplet analysis at Coso Geothermal. Bull Seismol Soc Am 88:1127-1143

Li L, Chen Q, Niu F, Su J (2011) Deep slip rates along the Longmen Shan fault zone estimated from repeating microearthquakes. J Geophys Res 116:B09310. https://doi.org/10.1029/2011JB008406

McEvilly TV, Casaday KB (1967) The earthquake sequence of September, 1965 near Antioch, California. Bull Seismol Soc Am 57:113-124

Nadeau RM, Johnson LR (1998) Seismological studies at Parkfield Vl: moment release rates and estimates of source parameters for small repeating earthquakes. Bull Seismol Soc Am 88:790-814

National Research Institute for Earth Science and Disaster Resilience (2019) NIED MOWLAS, National Research Institute for Earth Science and Disaster Resilience. https://doi.org/10.17598/NIED.0009

Niu F, Silver PG, Nadeau RM, McEvilly TV (2003) Migration of seismic scatterers associated with the 1993 Parkfield aseismic transient event. Nature 426:544-548

Okada T, Matsuzawa T, Hasegawa A (2003) Comparison of source areas of $M 4.8 \pm 0.1$ repeating earthquakes off Kamaishi, NE Japan: are asperities persistent features? Earth Planet Sci Lett 213:361-374

Omori F (1905) Horizontal Pendulum observation of earthquakes in Tokyo: similarity of the seismic motion originating at neighbouring centres. Publ Earthq Invest Commit 21:9-102

Rubinstein JL, Uchida N, Beroza GC (2007) Seismic velocity reductions caused by the 2003 Tokachi-Oki earthquake. J Geophys Res 112:B05315. https:// doi.org/10.1029/2006JB004440

Sato H, Hirata N, Koketsu K, Okaya D, Abe S, Kobayashi R, Matsubara M, Iwasaki T, Ito T, Ikawa T, Kawanaka T, Kasahara K, Harder S (2005) Earthquake source fault beneath Tokyo. Science 309:462-464

Schaff DP, Richards PG (2004) Repeating seismic events in China. Science 303:1176-1178

Shimazaki K, Nakata T (1980) Time-predictable model for large earthquakes. Geophys Res Lett 7:279-282

Stauder W, Ryall A (1967) Spatial distribution and source mechanism of microearthquakes in central California. Bull Seismol Soc Am 57:1317-1345

Taira T, Silver PG, Niu F, Nadeau RM (2009) Remote triggering of fault-strength changes on the San Andreas fault at Parkfield. Nature 461:636-640. https //doi.org/10.1038/nature08395

Tkalčić H, Young M, Bodin T, Ngo S, Sambridge M (2013) The shuffling rotation of the Earth's inner core revealed by earthquake doublets. Nat Geosci 6:497-502. https://doi.org/10.1038/NGEO01813

Tsujiura M (1973) Spectrum of seismic waves and its dependence on magnitude (I). J Phys Earth 21:373-391

Uchida N, Bürgmann R (2019) Repeating earthquakes. Annu Rev Earth Planet Sci 47:305-332. https://doi.org/10.1146/annurev-earth-053018-060119

Wessel P, Smith WHF (1998) New, improved version of the Generic Mapping Tools released. EOS Trans AGU 79:579

\section{Publisher's Note}

Springer Nature remains neutral with regard to jurisdictional claims in published maps and institutional affiliations. 